\title{
FOUR INNOVATIVE SOLAR COUPLED HEAT PUMP SOLUTIONS FOR BUILDING HEATING AND COOLING
}

\author{
David Chèze ${ }^{1}$, Alessandra Cuneo ${ }^{2}$, Carlo Macciòn ${ }^{2}$, Matteo Porta ${ }^{2}$, Giuseppe Dino ${ }^{3}$, Andrea \\ Frazzica $^{3}$ and Andrea Gabaldón 4 \\ ${ }^{1}$ Univ Grenoble Alpes, CEA, LITEN, INES, F-38000 Grenoble (France) \\ 2 RINA Consulting, Genova (Italy) \\ ${ }^{3}$ CNR ITAE, Messina (Italy) \\ ${ }^{4}$ CARTIF, Valladolid (Spain)
}

\begin{abstract}
Despite the huge primary energy consumption associated with heating and cooling (H\&C) demand in EU building stock, the share of installed renewable H\&C solutions is still marginal (i.e. 5\%). In order to speed up a transition towards the widespread application of renewable $\mathrm{H} \& \mathrm{C}$ in buildings, innovative solutions are designed to compete against traditional solutions. SunHorizon project aims to demonstrate the potential for a user-friendly and costeffective solution based on an optimized design and combination of commercial innovative solar technologies (thermal or/and PV) and Heat Pumps (HP). This paper presents how different technologies (two solar panels, three HPs and thermal storage) have been coupled in four different Technology Packages (TPs) to satisfy H\&C demand of both residential and tertiary buildings. Preliminary thermo-economic TRNSYS simulation results are presented about four demo sites in Latvia, Germany and Spain, to demonstrate such innovative solutions able to cover up to $80 \%$ of $\mathrm{H} \& \mathrm{C}$ demand with a reduction of greenhouse gas (GHG) emissions up to $70 \%$.
\end{abstract}

Keywords: solar panels, heat pumps, heating and cooling, buildings, electricity self-consumption, grid feed-in

\section{Introduction}

Buildings are responsible for $41 \%$ of EU energy consumption and $\mathrm{H} \& \mathrm{C}$ equals $55 \%$ of the total EU energy demand (ODYSSEE, 2018). This demand is mostly met by fossil fuels, with natural gas having the main share, while renewable energy sources (RES) remain marginal (5\%). However, according to the EC's H\&C Strategy, the $\mathrm{H} \& \mathrm{C}$ sector still accounts for $59 \%$ of total EU gas consumption, and almost half of EU's buildings have boilers with an efficiency rate below 60\% (IEA. 2018). Nevertheless, RES are becoming increasingly common and socially accepted. Therefore, to speed up a transition towards RES-based H\&C in buildings, innovative solutions are designed to compete against traditional solutions with equivalent or lower investment costs and payback times, while guaranteeing similar or better levels of comfort. Both residential and tertiary new buildings types are expected to become highly efficient. Currently, solar panels and Heat Pump (HP) are the most common and socially accepted RES Based H\&C solutions. Bringing together existing and mature HP and solar technologies guarantees a simple energy system nevertheless efforts are still required to refine their coupling, as they are used to be designed and operated separately. Solar and HP can form an integrated solution with several key advantages: high RES share and energy efficiency, low electricity and primary-energy demand, low $\mathrm{GHG} / \mathrm{CO}_{2}$ emission. HP are well suited to low-temperature needs as for well-insulated residential and tertiary buildings. In parallel solar thermal and PV reduces also the thermal and electricity demand in non-renovated envelopes. The current work is performed in the context of the SunHorizon project (H2020 Project GA818329) which objective is to analyze the performance of building-integrated solar and HPs solution specifics and their individual challenges towards saving Non-Renewable Primary energy (PEnren) via increased Renewable Energy Ratio (RER), cost reduction (optimized size, installation cost reduction etc.) and reliability (lifetime and reduced maintenance). Innovative components as the BH20 unique thermal compressor heat pump from BOOSTHEAT (BH), the Hybrid adsorption/compression chiller from FAHRENHEIT (FAHR), the high-vacuum flat thermal panels from TVP 
SOLAR (TVP) and the hybrid PVT panels from DualSun (DS) are integrated in four TPs including thermal energy water storage from RATIOTHERM (RT) and A-/B- WHP (reversible Air/Brine source to Water HP) from BDR THERMEA (BDR). Details on each specific technology could be found in SunHorizon website. Each TP aims at covering space heating (SH), domestic hot water (DHW) and/or space cooling (SC) demand of eight different demo sites (small and large residential buildings as well as tertiary buildings) across EU climates, local energy mix and costs in Germany, Spain, Belgium and Latvia (CEA et al., 2020). A quick outlook of the composition of the four TPs and the demo sites locations is illustrated in Tab. 1. In Section 2, the key aspects of the preliminary design and TRNSYS modelling with respect to TP1, TP2, TP3, TP4, in particular experience in the elaboration of compliant control rules between the manufacturers of the solar and HP system parts has been presented. Then, Section 3 essentially emphasizes noticeable characteristics and the respective estimated energy and costs savings through the analysis of the simulation results, referring to Key Performance Indicators (KPI) commonly used in solar and HP contexts (CARTIF et al., 2019).

Tab. 1: Technology packages

\begin{tabular}{|c|c|c|}
\hline heat pumps $\backslash$ solar panels & $\begin{array}{c}\text { Hybrid PVT } \\
\text { DUALSUN }\end{array}$ & $\begin{array}{c}\text { High-vacuum flat thermal } \\
\text { TVP SOLAR }\end{array}$ \\
\hline $\begin{array}{c}\text { Thermal compressor HP } \\
\text { BOOSTHEAT }\end{array}$ & $\begin{array}{c}\text { TP2: Mixed solar-assisted / } \\
\text { parallel integration in Riga } \\
\text { (Latvia) }\end{array}$ & $\begin{array}{c}\text { TP1: Parallel integration in Berlin } \\
\text { (Germany) }\end{array}$ \\
\hline $\begin{array}{c}\text { Hybrid adsorption/compression } \\
\text { cascade chiller } \\
\text { FAHRENHEIT }\end{array}$ & $\begin{array}{c}\text { TP3: Solar -driven thermal chiller } \\
\text { in Sant Cugat (Spain) }\end{array}$ \\
\hline $\begin{array}{c}\text { Reversible Air-water to water HP } \\
\text { BDR THERMEA }\end{array}$ & $\begin{array}{c}\text { TP4: Parallel integration in } \\
\text { Madrid (Spain) }\end{array}$ & \\
\hline
\end{tabular}

\section{SunHorizon technologies architecture and modelling}

\subsection{TP1 development and modelling}

The challenge of TP1 is to combine each other the TVP solar panels, BH HP and RT thermal storage separate technologies and controllers, while meeting each manufacturer objectives and pursuing replication perspective within SunHorizon and beyond in the future. Fig.1 shows the hydraulic layout agreed by the manufacturers that ensures parallel operation of TVP and BH on the SH and DHW demand. It enables direct use of TVP heat at possibly high temperature above the cold return line from the radiator space heating SH circuit, and DHW solar preheating from accumulated solar heat in RT tank, before $\mathrm{BH} 20$ gas burner ensures water is heated up to the desired temperature. It also mutualizes one outdoor fan coil to operate the $\mathrm{BH} 20$ unit during the heating season and to dissipate excess heat from the TVP collector. Apart from the new component for BH thermal compressor heat pump BH20, existing TRNSYS components have been used in the TP1 assembly system model. It runs annual simulation at 3 minutes time step to investigate dynamic component interactions and usual solar combisytem control rules summarized in Tab.2.
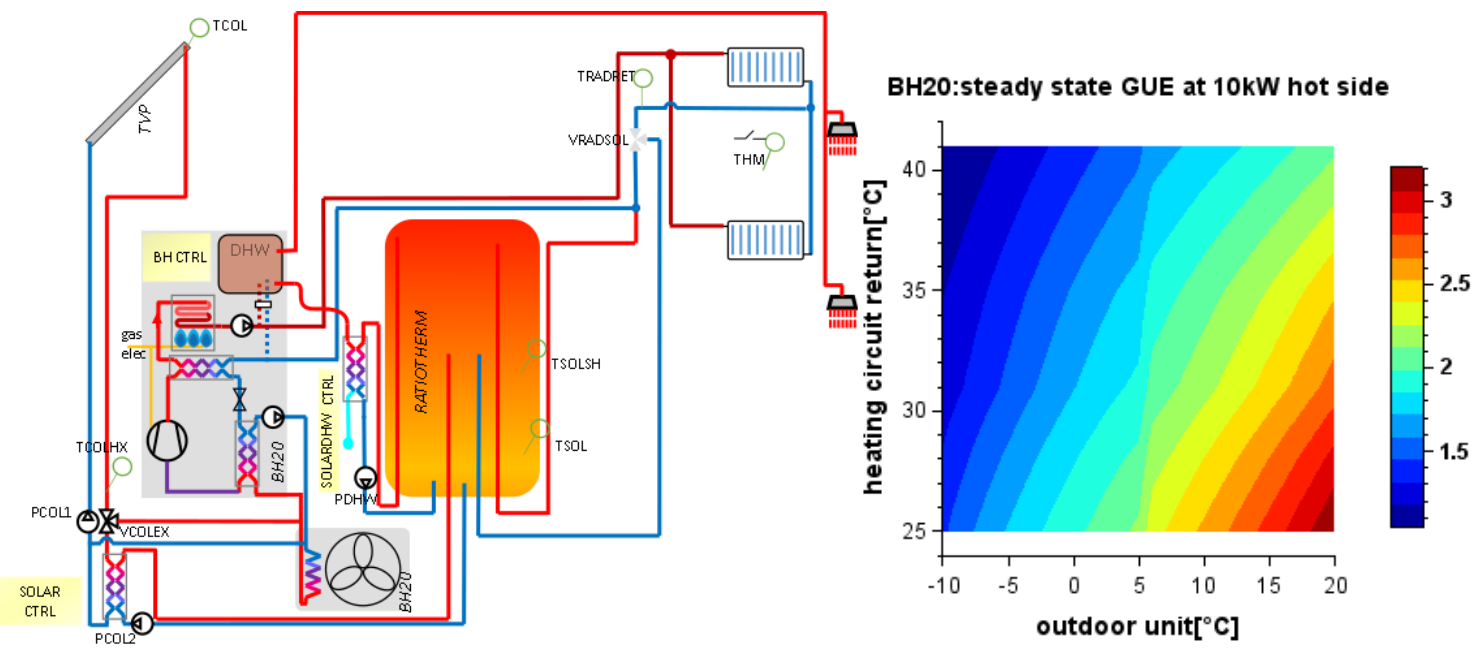

Fig. 1 TP1 concept for simulation and BH20 core Gas Utilization Efficiency (GUE) 
Solar circuit: The quasi-dynamic solar thermal collector model Type 832 maintained by SPF (Haller et al. 2012) is selected for the solar flat panels performance modelling. The Type 832 parameters for TVP thermal panels are set regarding the coefficients from EN ISO 9806 terminology $\eta_{0, \mathrm{~b}}=0.737 ; \mathrm{c} 1=0.504 \mathrm{~W} /\left(\mathrm{m}^{2} . \mathrm{K}\right) ; \mathrm{c} 2=0.006$ $\mathrm{W} /\left(\mathrm{m}^{2} \cdot \mathrm{K}^{2}\right) ; \mathrm{c} 3, \mathrm{c} 4, \mathrm{c} 6=0 / \mathrm{Kd}=0.957$. Default flat plate coefficients are assumed for IAM $\mathrm{b} 0=0.18$ and thermal capacitance $7000 \mathrm{~J} / \mathrm{K} \cdot \mathrm{m}^{2}$. The collector tilt is $60^{\circ}$ to match the slope of the roof in Berlin demo site and to reduce the overheating risk in summer when possible no DHW consumption during holidays. The solar tank is Type 340 model (Drück, 2006), the solar brine/water and DHW solar pre-heating heat exchangers are Type 5 models.

SH and DHW, heat demand models: The reference building connected to the TP1 is an historical house (beginning $\mathrm{XX}^{\text {th }}$ century) renovated in 2006, $284 \mathrm{~m}^{2}$ living area occupied by 7 peoples in three levels and thermal zones, under Berlin climate, modelled by multi-zone building TYPE56. The DHWcalc software (Jordan et al. 2005) was used to generate a synthetic yearly profile that matches the overall annual estimated consumption with realistic distribution of the consumption, statistical day-to-day variations. The configuration is reflecting a multifamily building, split into 2 households and average total daily consumption $300 \mathrm{~L}$ at $45^{\circ} \mathrm{C}$.

BH20 model: The $\mathrm{BH}$ unit is including the thermal gas fired compressor $\mathrm{CO}_{2}$ heat pump and the conventional condensing gas burner for DHW preparation (also used as backup of thermodynamic cycle on space heating complementary capacity request). The model is mainly relying on user Type 5837 and simulates the physical behavior including internal controller (extern sensors/actuators management) and issues performance outputs in steady state under the variable operating conditions: temperature at the cold $\left(-10 / 20^{\circ} \mathrm{C}\right)$ and hot $\left(30 / 55^{\circ} \mathrm{C}\right.$ in $\mathrm{SH}$, $10 / 85^{\circ} \mathrm{C}$ in DHW) sides of the heat pump, full or part load operation request (25-100\% nominal capacity $20 \mathrm{~kW}$ in SH operation). The performance outputs rely on continuous interpolation of the performance tables shared by BH from internal tests of the BH20 unit in space heating operation, shown in Fig. 1 (left). The maximum BH20 capacity parameter is variable from the $20 \mathrm{~kW}$ nominal capacity. The BH20 unit is linked to an outdoor fan coil, modelled by Type 91 heat air/brine exchanger. The air flow rate is controlled by Type5837 SFan 0-100\% output fan speed signal that is adjusting the nominal air flow rate to the current heat demand. The electricity consumption of the fan is approximated as a parabolic curve depending on the requested air flow-sfan signal, fitted from the BH20 manufacturer data. On the other hand, the BH Type 5837 is connected to a $65 \mathrm{~L} \mathrm{DHW} \mathrm{cylindrical} \mathrm{insulated}$ tank modelled by Type 340 .

\section{Tab. 2 TP1 overall control strategy}

\begin{tabular}{|l|l|}
\hline $\begin{array}{l}\text { TVP solar } \\
\text { thermal supply }\end{array}$ & $\begin{array}{l}\text { PCOL1 and PCOL2 are flowing solar heat into solar tank when TCOL is 5K higher than the } \\
\text { tank bottom temperature TSOL. } \\
\text { When RT max temperature is } 85^{\circ} \mathrm{C} \text { and TVP max outlet temperature is } 120^{\circ} \mathrm{C} \text {, outdoor fan } \\
\text { coil, diverter VCOLEX and solar pump PCOL1 are dissipating excess solar heat. }\end{array}$ \\
\hline DHW & $\begin{array}{l}\text { DHW heat exchanger is heating first from solar tank the sanitary cold water, assuming tank } \\
\text { side flow identical to the water draw then it flows into the Boosheat backup heated DHW } \\
\text { tank. }\end{array}$ \\
\hline Space heating & $\begin{array}{l}\text { SH radiator demand signal and flow are raised by thermostat THM with } 20^{\circ} \mathrm{C} \text { setpoint, } \\
\text { differential controller with }+1 \mathrm{~K} \text { deadband (radiator circuit heating curve with } 70^{\circ} \mathrm{C} \text { at }-12^{\circ} \mathrm{C} \\
\left.\text { and } 40^{\circ} \mathrm{C} \text { at } 15^{\circ} \mathrm{C}\right) . \\
\text { VRADSOL diverter is switching the return flow from radiator circuit to the solar pre-heating } \\
\text { tank when the mid-tank temperature is } 5 \mathrm{~K} \text { above otherwise the solar tank is bypassed. }\end{array}$ \\
\hline BoostHeat & $\begin{array}{l}\mathrm{CO} 2 \text { thermodynamic cycle activated for space heating with support of auxiliary gas burner } \\
\text { to ensure the heating curve flow temperature up to } 20 \mathrm{~kW} \text {. } \\
\text { The DHW boostheat tank set point temperature is } 55^{\circ} \mathrm{C} \text {, heated up by auxiliary gas burner. }\end{array}$ \\
\hline
\end{tabular}

\subsection{TP2 development and modelling}

The second TP is focused in the combination of BH HP with hybrid-PVT panels from DualSun together with a stratified thermal storage manufacturer by RT to be installed in a small residential building in Riga. The building is a privately owned single-family residential house built in 2013, with a heated area of $234.8 \mathrm{~m} 2$ distributed into two floors. The existing system (Gas boiler) will be integrated with the new system as a back-up service (e.g. during first operational tests, etc.). A model of the SunHorizon system has been produced in TRNSYS 18 in order to preliminary assess its performance. 


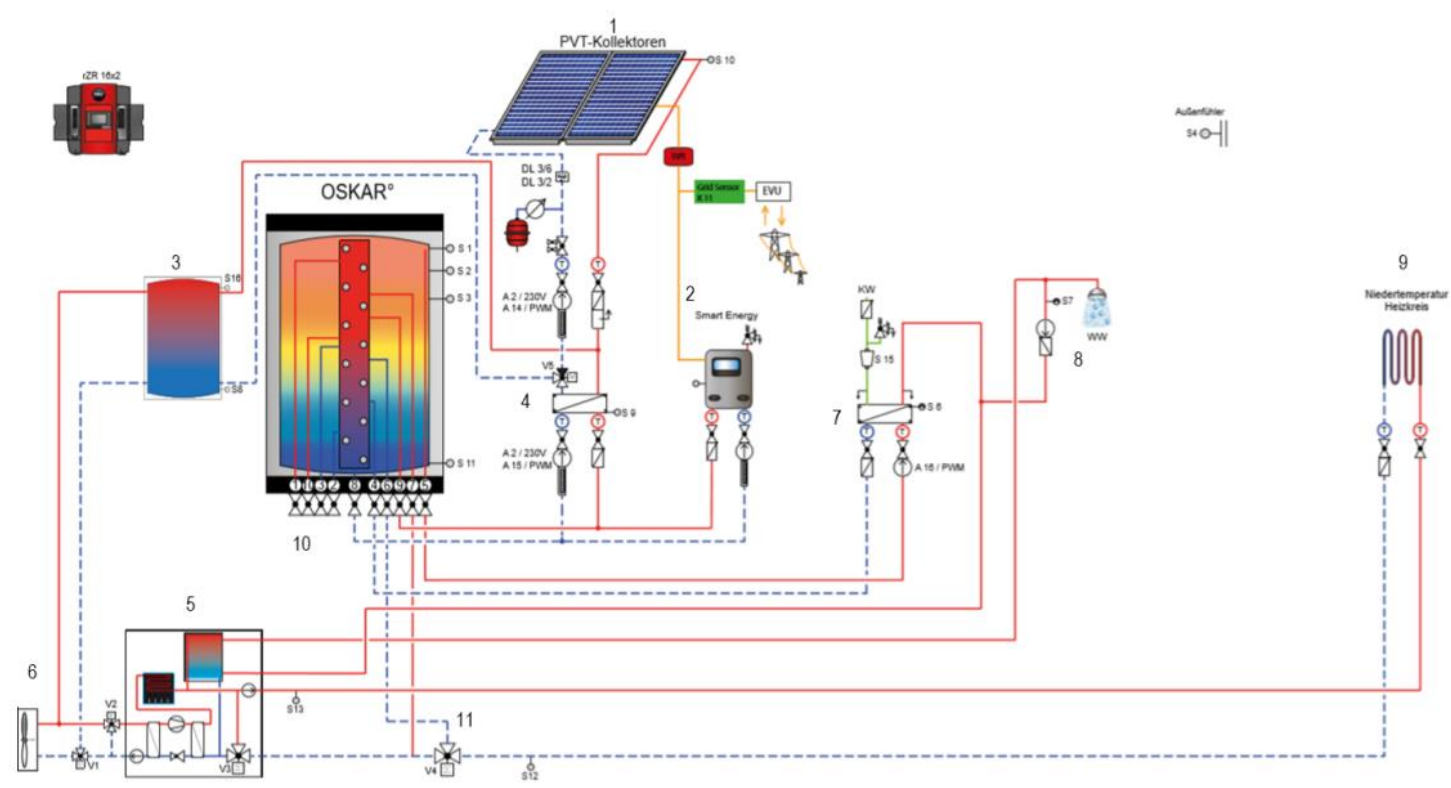

Fig. 2 - TP2 Schematics for Riga demosite

The Fig. 2 shows the SunHorizon TP2 schematics. Next, a description of the devised concept is presented according to the control strategy description in Tab. 2. The DualSun PVT panels (1) can heat up the stratified tank provided by RT (10) through a direct heat exchanger (4) when the outlet temperature from PVT panels is higher than the RT tank (S3). When the temperature is lower, a three ways valve is switched to connect the PVT panels to the glycol tank (3) in order to run the evaporator of the BH heat pump unit (5). PV production from (1) is mainly used to cover electricity demand from the building. When the electrical production exceeds the building's demand, then the smart energy electrical heater (2) can be used to heat up the RT tank (10) till the maximum temperature set for the tank is reached. This way, electricity is almost always self-consumed. The evaporator of the BH unit can be driven by (1)+(3) or by an outdoor dry cooler (6). BH unit heats up the flow in two phases. First, the water is heated up in the condenser (up to $50^{\circ}$ ). Second, if the desired temperature is higher than the condenser outlet, a secondary burner heats up the flow up to $70^{\circ} \mathrm{C}$. DHW demand will be preheated by heat exchanger (7) with the RT tank and later will flow to the DHW tank inside the BH unit to be heated up by the BH unit (5). The radiator stream will be preheated first with the RT tank through a three-way valve (11), and then by the BH unit (5). The BH unit is modelled in TRNSYS in a similar way as in TP1. DualSun PVT panels are modelled in TRNSYS using Type 816, which constitutes a dedicated simulation module with a nominal photovoltaic power of $310 \mathrm{~W}$ and coefficients from EN ISO 9806 terminology of $\eta_{0, \mathrm{~b}}=0.559 ; \mathrm{c} 1=15.8 \mathrm{~W} /\left(\mathrm{m}^{2} . \mathrm{K}\right)$; $\mathrm{c} 2=0 \mathrm{~W} /\left(\mathrm{m}^{2} \cdot \mathrm{K}^{2}\right) ; \mathrm{c} 3, \mathrm{c} 4, \mathrm{c} 6=0$. The baseline consumption of the building has been evaluated considering weather profile and users profiles. The users' profiles in terms of DHW, space heating and electricity consumption has been modelled using CRESTmodel (McKenna and Thomson, 2016) and calibrated according to the total annual consumption derived from the bills.

Heating circuit:When the temperature of the RT tank at the center-bottom position within the tank is higher than the temperature of the return heating circuit, the water is preheated at the RT Tank. A mixing valve is used to control the supply temperature of the radiator according to the selected set point taking into account the return temperature. The two radiatiors are connected to the primary heating circuit, since they work with the same water temperature. The pump flow rate is fixed and is equal to the sum of the flow rate of two radiator. Then to provide the right flow rate to the radiators, two diverters are used.

Hot water circuit: The DHW is first preheated with the RT through a $\mathrm{HX}$ and later, it is streamed to the $\mathrm{BH}$ dedicated tank. The $\mathrm{BH}$ tank is maintained at a given temperature $\left(\right.$ e.g. $60^{\circ} \mathrm{C}$ ), in order to ensure the DHW supply temperature requested by the final users. The BH DHW tank is heated by the BH unit, which stops to provide heat to the radiators and heat up the tank. When the tank is heated the $\mathrm{BH}$ unit return to provide heat to the radiators. When providing heat to the DHW tank, the BH types turns into the control mode 2, that means that has a behaviour equal to a traditional condensing boiler of $18 \mathrm{~kW}$.

Solar circuit: The solar circuit is activated when the solar irradiation is higher than $540 \mathrm{~kJ} / \mathrm{hr} / \mathrm{m} 2$ and the outlet temperature of DualSun panels is higher than the glycol tank temperature or the RT tank temperature. The heating 
of the RT tank has the priority. When the outlet temperature is lower than the bottom temperature of the tank, the flow is then switched towards the glycole tank. Due to the local legislation in Latvia, the maximum allowed installed installed capacity of a micro generator used for net metering is $11.1 \mathrm{~kW}$, limiting though the maximum number of panels at $35(10.9 \mathrm{kWp})$.

Tab. 2 Control strategies

\begin{tabular}{|l|l|}
\hline $\begin{array}{l}\text { DualSun } \\
\text { thermal supply }\end{array}$ & $\begin{array}{l}\text { DualSun supply RT if DualSun outlet temperature is }>=\mathrm{RT} \text { temperature }+5^{\circ} \mathrm{C} \\
\text { DualSun supply Glycol Tank if DualSun outlet temperature is }<\mathrm{RT} \text { temperature }+5^{\circ} \mathrm{C} \text { and } \\
>\text { Glycol Tank temperature. }\end{array}$ \\
\hline RT Tank & $\begin{array}{l}\text { RT max temperature: } 80^{\circ} \mathrm{C} \\
\text { RT Preheating circuit is activated if the return temperature from the emission system is }<= \\
\text { RT temperature }-2^{\circ} \mathrm{C}\end{array}$ \\
\hline $\begin{array}{l}\text { Electricity } \\
\text { management }\end{array}$ & $\begin{array}{l}\text { Electricity is self-consumed if demand and production are simultaneous. } \\
\text { Electricity surplus is supplied to the grid until the total surplus produced reaches the post } \\
\text { retrofit electricity consumption. } \\
\text { Electricity is provided to smart energy heater once the maximum surplus which can be } \\
\text { supplied to the grid is reached. }\end{array}$ \\
\hline $\begin{array}{l}\text { Evaporator of } \\
\text { BH }\end{array}$ & $\begin{array}{l}\text { The BH's evaporator can be driven by an outdoor drycooler or the glycol loop connected to } \\
\text { the DualSun panels. Whenever the glycol tank temperature is higher than the outdoor air } \\
\text { temperature, the use of the glycol tank as evaporator is prioritized (if BH system is required). }\end{array}$ \\
\hline
\end{tabular}

\subsection{TP3 development and modelling}

TP3 illustrated in Fig. 3 will be installed in a tertiary building (civic center) located in Sant Cugat del Vallès (Spain), built in 2006. The heating and cooling installation of the existing system is based on Reversible air to water heat pump: $93.6 \mathrm{~kW}$ (nominal cooling capacity) $-96.3 \mathrm{~kW}$ (nominal heating capacity) and Air handling unit (AHU): $110 \mathrm{~kW}$ (cooling capacity) $-67.78 \mathrm{~kW}$ (heating capacity). The conditioned area and volume are respectively $816 \mathrm{~m}^{2}$ and $3400 \mathrm{~m}^{3}$. A simulation of actual and future HVAC plant was performed by means of two different software: First, the IESVE simulation is run to obtain the heating and cooling $(\mathrm{H} / \mathrm{C})$ loads from the building model, then its results are used as input for H/C system plant simulated in TRNSYS18. The TP3 system was modelled in TRNSYS by considering the datasheet of each installed equipment. The AHU was modelled component by component, while the heat pump was modelled by a calculator that implements equation obtained from a statistical analysis of operating data declared in the official datasheet. The non-linear polynomial eq. 1 correlates operating temperatures with real performances of the components.

$\mathrm{f}\left(\mathrm{T}_{\text {air }}, \mathrm{T}_{\text {water_out }}\right)=\mathrm{p} 00+\mathrm{p} 10 * \mathrm{~T}_{\text {air }}+\mathrm{p} 01 * \mathrm{~T}_{\text {water_out }}+\mathrm{p} 20 * T_{\text {air }}{ }^{2}+\mathrm{p} 11 * \mathrm{~T}_{\text {air }} * \mathrm{~T}_{\text {water_out }}$ (eq. 1)

The TP3 system will be integrated with the existing HVAC; TVP panel, FAHR hybrid adsorption chiller and RT stratified tank will be integrated, the new system will be connected in series upstream to the existing heat pump (Fig. 3), the existing primary pump will be changed with a variable speed one. The only heat source is the solar one, TVP panel will produce as much thermal energy as possible with a maximum temperature range between $70^{\circ} \mathrm{C}$ and $100^{\circ} \mathrm{C}$. During winter, the hot water produced by TVP panels will support the existing plant and is directly delivered to the existing heat pump, in summer it supplies the FAHR thermally driven chiller. FAHR Hybrid Chiller (HC) consists of two components: a vapour compression water to water chiller and an adsorption one, they are connected in parallel to a cold buffer tank and then to the existing chiller. The nominal cooling power are $50 \mathrm{~kW}$ for the vapour compression chiller and $20 \mathrm{~kW}$ for the sorption one. TVP panel surface is $220 \mathrm{~m}^{2}$ south oriented (azimuth $=0$ ) and tilted $30^{\circ}$, the volume of stratified storage is $10 \mathrm{~m}^{3}$.

As for the existing reversible HP, the Hybrid Chiller (HC) was modelled by implementing performance equations. The compression unit was modelled through a performance equation analogous to eq. 1. For the sorption unit a linear model that considers the three operating temperatures (HT-high temperature, MT-recooling temperature, LT-cooling temperature) was implemented. Source data were provided by FAHR and converted in a statistical correlation. In this case the temperatures of water inlet inside the machine were considered, the correlation was calculated both for cooling power and COP.

$\mathrm{f}\left(\mathrm{HT}_{i n}, \mathrm{MT}_{i n}, \mathrm{LT}_{i n}\right)=\mathrm{I}+\mathrm{a} * \mathrm{HT}_{\text {in }}+\mathrm{b} * \mathrm{MT}_{\text {in }}+\mathrm{c} * \mathrm{LT}_{\text {in }} \quad$ (eq. 2) 


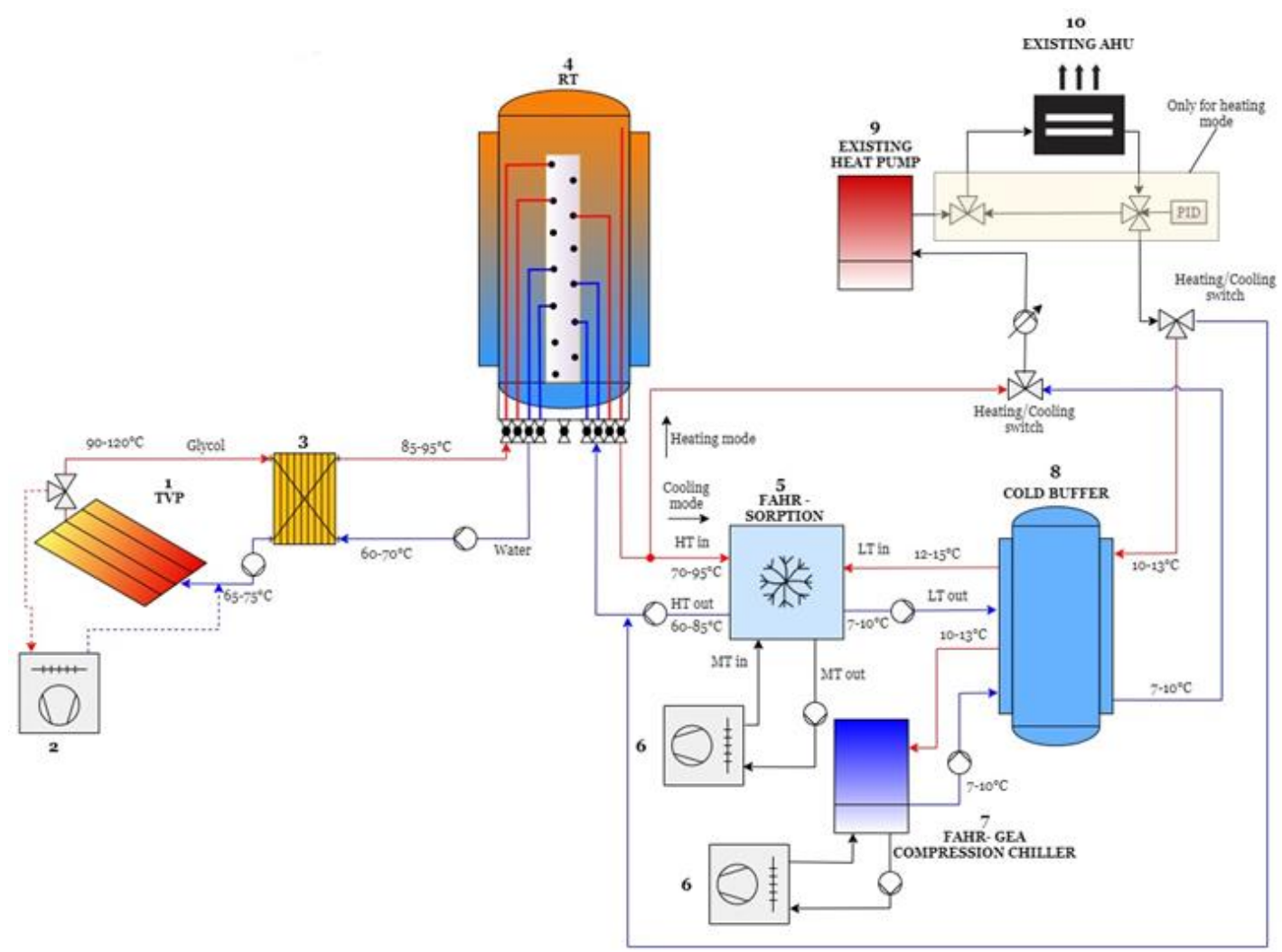

Fig. 3 Integration between existing system and SunHorizon TP3

In Tab. 3, the control strategy considers the behavior of the existing plant deduced from the preliminary data retrieved from the existing monitoring system.

Tab. 3 Control strategy for the existing system

\begin{tabular}{|c|c|}
\hline Component & Signal logic \\
\hline AHU fan (type 662) & $\begin{array}{r}\text { Aquastat controller based on indoor air temperature setpoint and daily schedule (6:00- } \\
22: 00): \text { T setpoint } 25^{\circ} \mathrm{C} \text { (Cooling mode) }-21^{\circ} \mathrm{C} \text { (Heating mode) }\end{array}$ \\
\hline AHU control dump & $40 \%$ recirculation air ratio (fixed by demo site owners) \\
\hline pump (type 654) & Signal pump $=1$ following daily schedule (6:00-22:00) \\
\hline Existing HP (eq. 1) & $\begin{array}{r}\text { HP 4 power levels: } 0 \%-37 \%-63 \%-100 \% \text {. PID controller based on temperature } \\
\text { setpoint of HP water outlet: } 40^{\circ} \mathrm{C} \text { for heating and } 7{ }^{\circ} \mathrm{C} \text { for cooling }\end{array}$ \\
\hline
\end{tabular}

A summary of control strategy for each component of the TP3 is reported in Tab. 4. The general controls implemented in the existing HVAC system is only changed regarding the primary pump.

Tab. 4 control strategy for SunHorizon model

\begin{tabular}{|c|c|}
\hline Component & Control description \\
\hline $\begin{array}{l}\text { TVP temperature } \\
\text { control }\end{array}$ & $\begin{array}{l}\text { Type } 539 \text { (TVP solar panel), configured to internally vary the flowrate aiming at } \\
\qquad 95^{\circ} \mathrm{C} \text { outlet setpoint temperature }\end{array}$ \\
\hline Safety diverter valve & Aquastat controller based on TVP water outlet temperature (setpoint $100^{\circ} \mathrm{C}$ ). \\
\hline $\begin{array}{l}\text { HC Dry Cooler } \\
\text { settings }\end{array}$ & $\begin{array}{l}\text { Dry cooler types } 511 \text {, configured to modulate fan speed aiming at } 25^{\circ} \mathrm{C} \text { outlet fluid } \\
\text { temperature }\end{array}$ \\
\hline HC Sorption unit & Aquastat controller based on temperature inlet of sorption chiller (setpoint $8^{\circ} \mathrm{C}$ ) \\
\hline
\end{tabular}




\begin{tabular}{|c|c|}
\hline HC Compression unit & $\begin{array}{r}\text { Chiller 2 power levels: 50\% and 100\%. PID controller based on temperature outlet } \\
\text { from the chiller (setpoint } 7{ }^{\circ} \mathrm{C} \text { ) }\end{array}$ \\
\hline $\begin{array}{c}\text { Tempering valve }- \\
\text { AHU hydronic loop } \\
\text { (heating operation) }\end{array}$ & $\begin{array}{c}\text { The tempering valve mixes the hot water delivered by TVP panel with return warm } \\
\text { water from AHU coil during winter operation whener TVP production is higher } \\
\text { than hot water AHU inlet set point }\left(40^{\circ} \mathrm{C} \text { ) }\right.\end{array}$ \\
\hline $\begin{array}{c}\text { Primary pump } \\
\text { (variable speed) }\end{array}$ & $\begin{array}{r}60 \%-100 \% \text { signal, the intensity of signal is proportional to the difference between } \\
\text { the temperature of water outlet from AHU coils and the setpoint }\end{array}$ \\
\hline
\end{tabular}

\subsection{TP4 development and modelling}

TP4 couples BDR HPs with DualSun PVT is shown in Fig. 4 applied in Madrid demo case, and consists of DualSun PVT panels (1) driving the evaporator of a Brine Water HP (BWHP) (3), an Air Water HP as back-up (6) and two storage tanks from RT: one for space heating and space cooling demand(4), and another one for DHW demand(5). The solar driven heat pump allows to store the solar energy in RT tanks via the BWHP as well as producing PV electric energy to drive both HP and cover partially the electrical demand of the building. A small glycol buffer (2) is installed between the BWHP and PVT collectors to de-couple the flow rates. The AWHP one includes an electric resistance $(2 \mathrm{x} 6 \mathrm{~kW})$ to have the possibility to perform thermal shock as legionella preventive control - in case of need.

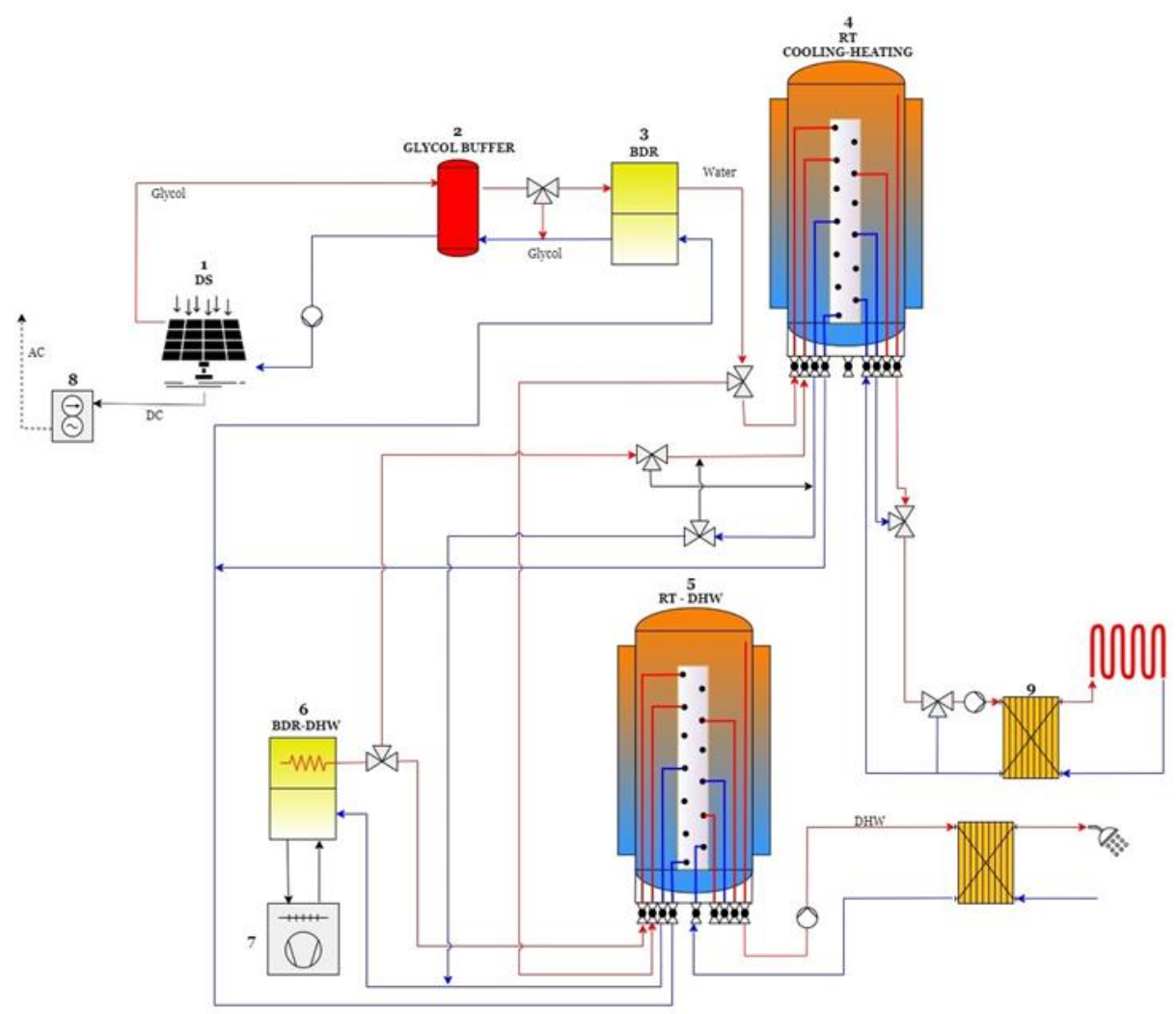

Fig. 4 Integration between existing system and SunHorizon TP4

Modelling approach: In TRNSYS the DualSun PVT panels are modelled using Type 816, using the same coefficients as in TP2. The collector tilt is set to $35^{\circ}$, to optimize the thermal and PV production in Madrid. The small glycol buffer is modelled using Type 4 a with default values and a volume of $0.2 \mathrm{~m} 3$. BWHP is modelled using Type 927 using the performance map of GSHP 9 TR-E model from BDR, which has a capacity of $9 \mathrm{~kW}$ and a COP of 3.42 (B0/W45, EN14511). The temperature at the entrance of the BWHP is limited to a maximum of $35^{\circ} \mathrm{C}$ and minimum of $-15^{\circ} \mathrm{C}$ with Type 953 (tempering valve) for safety reasons. The AWHP is modelled using 941 using the performance map from HP HPI Evolution model 27 TR-2 from BDR, which has a capacity of $24.4 \mathrm{~kW}$ and COP 3.94 (A7/W35, EN14511). Heat pump flow rates are designed to supply a temperature difference of $5^{\circ} \mathrm{C}$, whereas the solar loop flow rate is set to $60 \mathrm{~kg} / \mathrm{h} \cdot \mathrm{m} 2$. The building where TP4 is applied consists of a retrofitted social housing building in Madrid. The building demand is estimated using Design Builder resulting 
in a space heating and space cooling demand of $31.8 \mathrm{kWh} / \mathrm{m} 2$ and $9.36 \mathrm{kWh} / \mathrm{m} 2$, respectively. Fancoils are modelled using Type 91 to heat or cool the air of the Type 56 building. DHW consumption is estimated in 122 $\mathrm{kWh}$ /person using CREST software demand. As baseline case, DHW and SH is provided by a boiler with an efficiency of $80 \%$ and cooling is satisfied with individual splits with an EER of 2.5.

Control strategy: The DualSun solar thermal loop is switch on whenever the temperature at the outlet of the solar collector is five degrees greater than the bottom temperature of the buffer tank, whereas the HP's operation depends on its efficiencies. HP efficiencies are modelled with empirical equations depending on the supply and evaporator's temperature. Tab. 5 control modes are modelled in MATLAB and coupled with TRNSYS via Type155, to assess the efficiency every 5 minutes and switch on the heat pump with the highest efficiency whenever there is DHW, SH or SC request. When there are two demand requests, DHW is supplied with the HP with the highest efficiency. To avoid reversing the mode of the BWHP too many times, the cooling reverse mode is only switched on whenever there is an excess of PV production and no DHW request. When the maximum or minimum temperature at the inlets of the HPs are reached, the control signal is disabled. The MATLAB program takes into account the different operation modes in the different seasons and DHW is always prioritized (See Tab. 5). DHW or SH is requested whenever the top tank temperature is lower than the setpoint temperature $\left(50^{\circ} \mathrm{C}\right.$ and $45^{\circ} \mathrm{C}$, respectively). SC is requested whenever the bottom tank temperature is higher than the cooling setpoint temperature $\left(15^{\circ} \mathrm{C}\right)$

Tab. 5 Control Modes in TP4 for selection of HP supply types to meet the thermal demand types

\begin{tabular}{|c|c|c|c|}
\cline { 2 - 4 } \multicolumn{1}{c|}{} & Only AWHP on & Only BWHP on & Both on \\
\hline DHW request & Mode 1b & Mode $2 \mathrm{~b}$ & $\begin{array}{c}\text { Mode } 3 \mathrm{~b}: \text { AWHP }>\text { DHW, } \\
\text { BWHP }>\text { SH }\end{array}$ \\
\hline $\begin{array}{c}\text { SH request } \\
\text { (heating season) }\end{array}$ & Mode 1a (heating) & Mode 2a (heating) & $\begin{array}{c}\text { Mode 3a: } \text { BWHP }>\text { DHW, } \\
\text { AWHP }>\text { SH }\end{array}$ \\
\hline $\begin{array}{c}\text { SC request } \\
\text { cooling season) }\end{array}$ & Mode 1a (cooling) & $\begin{array}{c}\text { Mode 2a (cooling). Only if } \\
\text { excess of PV production } \\
\text { and no DHW request }\end{array}$ & $\begin{array}{c}\text { Mode 3a: BWHP }>\text { DHW, } \\
\text { AWHP }>\text { SC }\end{array}$ \\
\hline
\end{tabular}

\section{Results and discussion}

\subsection{TP1 results}

The parametric study for the preliminary sizing from simulations of solar field and tank regarding the nonrenewable energy and Customer Bill Reduction (CBR) savings is balanced by the amount of solar heat dissipated, since the impact of the solar field overheating protection emerged from industry partners and demo site responsible discussions. The Fig. 5 shows a turning point around 800L solar tank volume for both CBR costs and 10\% limitdissipated heat curves that mostly selected the TP1 configuration as $10 \mathrm{~m}^{2} \mathrm{TVP}$ solar panels, $0.8 \mathrm{~m}^{3} \mathrm{RT}$ tank and 20kW BH unit. The Tab. 6 shows its performance results, considering the existing heating system is gas boiler and SDHW with assumed solar fraction of 50\%, consuming 37.2 MWh PE, that means $2.1 \mathrm{k} €$ costs and 7.4 tons $\mathrm{CO}_{2, \text { eq }}$ emissions per year. The $63 \%$ TVP solar useful heat efficiency outperforms by $30 \%$ its traditional flat plate competitor (same area) that leads to 3\% extra PE savings. The integration of solar thermal TVP and RT tank from BH20 single unit is increasing from 25 to $36 \%$ the $\mathrm{f}_{\text {sav,PEnren }}$ and the GUE from 130 to $132 \%$, mostly by reducing the share of high temperature DHW demand in total BH20 heat supply. 

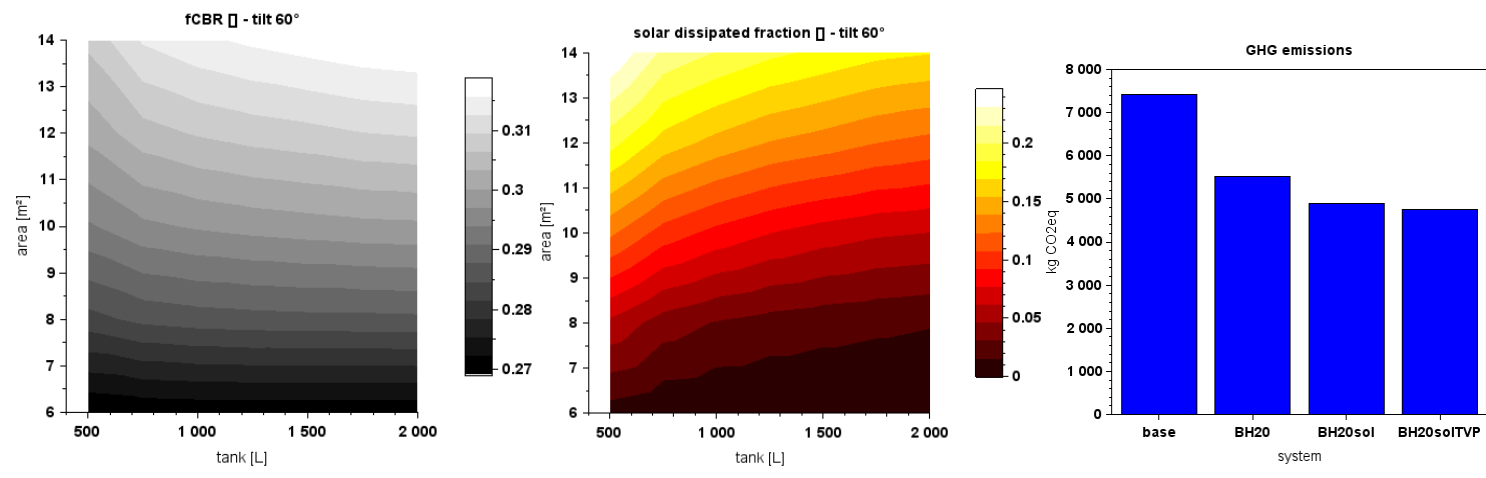

Fig. 5 Analysis of bill reduction (left), overheating (mid) and system configuration effect (right)

Tab. 6 Estimated annual KPIs for TP1 in Berlin demo site

\begin{tabular}{|c|c|c|c|c|c|c|c|}
\hline $\boldsymbol{\eta}_{\boldsymbol{T V P}, \mathbf{5} 3^{\circ} \boldsymbol{C}}^{\text {gros }}$ & $\boldsymbol{f}_{\text {sol,th }}$ & $\boldsymbol{d T t a n k}$ & $\boldsymbol{G U E}$ & $\boldsymbol{R E R}$ & $\boldsymbol{f}_{\text {sav, PEnren }}$ & $\boldsymbol{f}_{\text {sav, }, \boldsymbol{G H G}}$ & $\boldsymbol{f}_{\boldsymbol{C B R}}$ \\
\hline $63 \%$ & $14 \%$ & $34 \mathrm{~K}$ & $132 \%$ & $31 \%$ & $36 \%$ & $36 \%$ & $30 \%$ \\
\hline
\end{tabular}

\section{$3.2 \mathrm{TP} 2$ results}

The simulation has been performed considering 35 maximum number of panels $\left(58 \mathrm{~m}^{2}\right)$ and an heat pump of $20 \mathrm{~kW}$ to be installed and varying the dimension of the storage to understand the optimum situation that allow to have a balanced energy savings reduction and customer bill reduction. To calculate the energy cost, the discount obtained on the electricity price thanks to the net metering has been considered: the extra electricity produced and not selfconsumed, can be supplied to the grid. Based on a yearly calculation, a discount of $35 \%$ on the energy price is considered for an amount of energy equal to the extra energy supplied. This amount cannot exceed the yearly electricity consumption. From the Fig. 6, the KPIs about reducing energy consumption, greenhouse gases emissions and energy cost show that the tank size has a limited effect ( 1-2 \%) on savings, either fsav or fCBR (39\% is about $745 €$ ). An on-going optimization of the set of control parameters is aiming to improve further these KPIs.

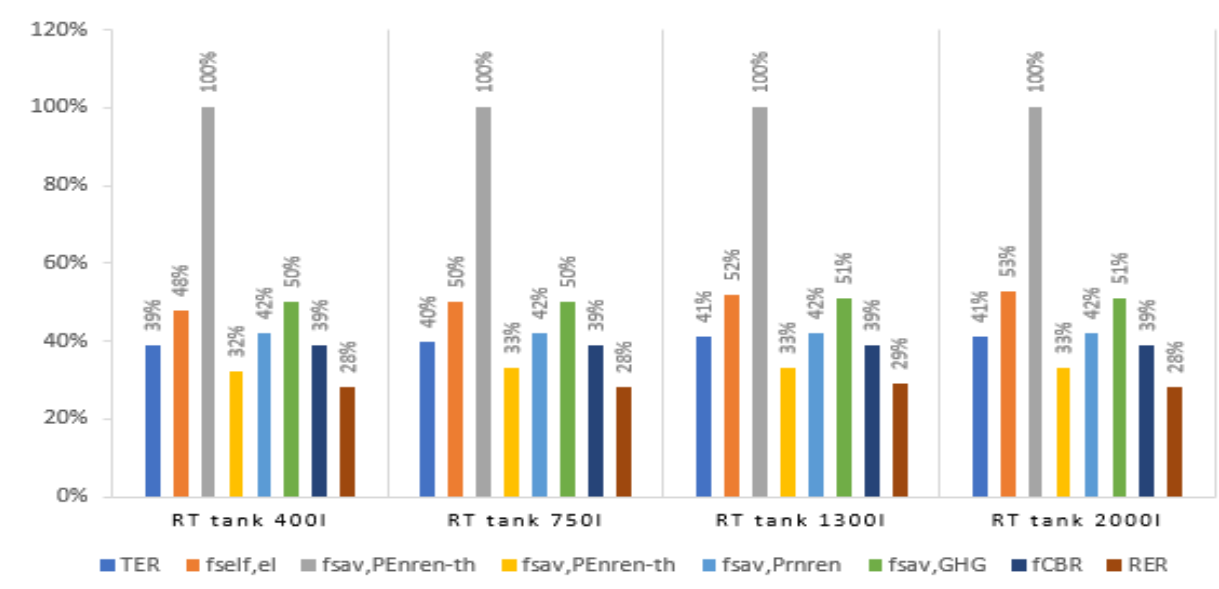

Fig. 6 Simulated performance of TP2 configurations in Riga demo case

Tab. 7 Simulated performance of TP2 selected 1300L configuration in Riga demo case.

\begin{tabular}{|c|c|c|c|c|c|c|c|c|}
\hline $\boldsymbol{f}_{\text {self,el }}$ & $\boldsymbol{T E R}$ & $\boldsymbol{G U E}$ & $\boldsymbol{R E R}$ & $\boldsymbol{f}_{\text {sav,PEnren-el }}$ & $\boldsymbol{f}_{\text {sav,PEnren-th }}$ & $\boldsymbol{f}_{\text {sav,PEnre? }}$ & $\boldsymbol{f}_{\text {sav,GHG }}$ & $\boldsymbol{f}_{\text {CBR }}$ \\
\hline $52 \%$ & $41 \%$ & $125 \%$ & $29 \%$ & $100 \%$ & $33 \%$ & $42 \%$ & $51 \%$ & $39 \%$ \\
\hline
\end{tabular}

\section{$3.3 \mathrm{TP} 3$ results}

As detailed in CEA et al. 2020, a tailored hourly weather file for the year 2019 relying on interpolation from 
Athenium Analytics (an iScan service provided in IESVE) and Meteonorm files was developed to account for realistic user demand in both simulations (building and system). Several analyses performed before the simulation addressed a first sizing of the main components, then, the simulation results assessed the optimal compromise between theoretical optimal size and technical issues. The main technical matters are related to the optimal coupling between solar production and sorption demand, the configuration of hybrid chiller and its consequent sizing, the correct coupling between existing system and TP installation. The hybrid chiller consists in parallel connection of $50 \mathrm{~kW}$ vapor compression module and $20 \mathrm{~kW}$ sorption unit (nominal cooling power). TVP panel surface is $220 \mathrm{~m}^{2}$ south oriented and tilted $30^{\circ}$, the volume of stratified storage is $10 \mathrm{~m}^{3}$. The main result from Tab. 8 is the reduction of $33.4 \%$ of electrical energy consumption and fsol-sh solar fraction in heating season close to one. During summer the hybrid chiller covers the $57.7 \%$ of cooling energy supply with an increase of energy efficiency and energy saving (Fig.7). Moreover, the sorption unit supplies cooling energy with a very high efficiency due to its low electrical demand and to its renewable source for driving power. The hybrid chiller coupled with a renewable energy source (TVP) let to achieve one of the main goal of Sunhorizon project regarding $33 \%$ PEnren savings and 52\% renewable energy ratio. The control strategy of hybrid system plays a crucial role to balance the sorption and vapour compression cooling production. Tab. 4 shows different temperature set point for each unit in order to maximise the sorption production and the solar energy supply. The investigation of additional sorption modules installation shown severe increase of auxiliaries' electricity consumption, not balanced by enhanced cooling power. In the sizing of TVP solar field, it shows an overproduction that can't be stored beyond the tank maximum safety temperature, therefore it is dissipated. To minimize the solar energy waste two ways were investigated: reduce the solar field area or increase the stratification tank volume. The first way is not suitable because of the significant decrease of sorption cooling production, from the second, arises technical troubles regarding the installation and not significant benefits in terms of energy storage. The solar energy wasted during summer amounts to $31.9 \%$ of production, in winter is $24.1 \%$; during the periods in which there is no heating or cooling demand the solar energy production must be fully wasted since there are no DHW load. Tab. 6 reports the main KPIs estimated for TP3 in Sant Cugat where the relative values are referring to absolute values of PESnren $43994 \mathrm{kWh}, \mathrm{GHGsav} 7825 \mathrm{kgCO}_{2}$, eq and CBR $5270 €$. Furthermore, TP3 achieved better indoor comfort conditions than the existing H/C system by reducing the HCI from 817 to 83 K.h and CCI from 1748 to 1360 K.h.

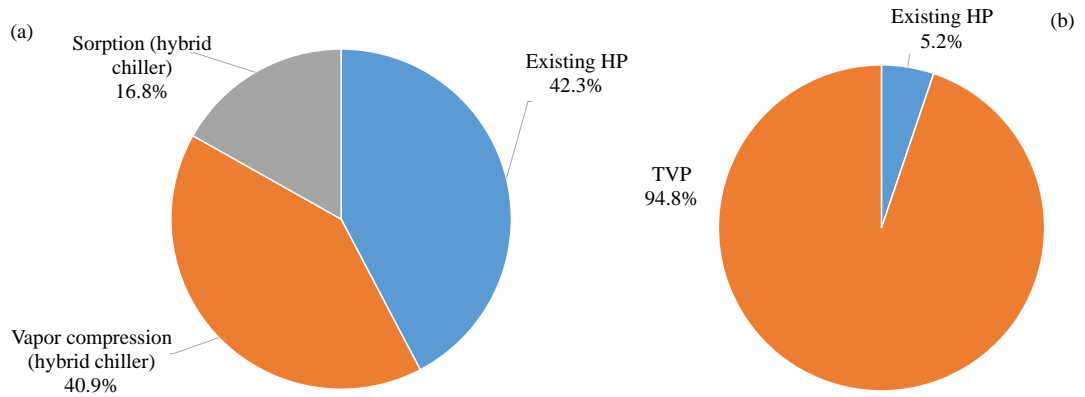

Fig. 7: Source distribution for cooling (a) and heating (b) energy supply

Tab. 8 TP3 main annual KPIs

\begin{tabular}{|c|c|c|c|c|c|c|c|}
\hline $\boldsymbol{\eta}_{\boldsymbol{T V P}, \mathbf{7 6 ^ { \circ } \mathrm { C }}}^{\boldsymbol{g r o s S}}$ & $\boldsymbol{f}_{\text {sol,th }}$ & $\boldsymbol{f}_{\text {sol,sh }}$ & $\boldsymbol{S E E R}$ & $\boldsymbol{R E R}$ & $\boldsymbol{f}_{\text {sav, PE }}$ nren & $\boldsymbol{f}_{\text {sav }, \mathrm{GHG}}$ & $\boldsymbol{f}_{\boldsymbol{C B R}}$ \\
\hline 0.51 & 18.27 & 0.95 & 6.9 & $52 \%$ & $33.4 \%$ & $33.4 \%$ & $33.4 \%$ \\
\hline
\end{tabular}

\section{$3.4 \mathrm{TP} 4$ results}

A parametric study is performed to size the system components, varying the volume of the RT tanks, slope of the DualSun PVT modules and setpoint temperatures. From the main results illustrated in Fig. 8, the system is not sensible with the variation of the volume of the RT tank, but as the volume increases the primary energy savings increases slightly. The lower the tilt inclination, the lower the PV production and the system achieved more PEnren savings between $35-45^{\circ}$ (there is not significant variation between this two). By increasing the DHW setpoint to $60^{\circ} \mathrm{C}$ in the tank, the savings are reduced in $2.5 \%$ points, while by moving the position of the monitored temperature to the middle-top tank (a relative height of 0.7 ), the savings are reduced in $0.5 \%$ (more energy is charged in the tank). By increasing the capacity of the DHW tank, the primary energy savings increase $0.1 \%$ as 
well as the RER. The same happens by increasing the capacity of the SH/SC tank. Nevertheless, due to space limitation in the technical room, the capacity of both tanks are limited to a height of 1.5 meters and a capacity of $1.3 \mathrm{~m}^{3}$, and $1 \mathrm{~m} 3$ respectively, in order to ensure stratification. Furthermore, the current control strategy is compared with a temperature-dependent control strategy that does not consider the efficiencies of the BDR HPs (reference case vs. simpler control in Fig. 7). This simple strategy switches on the BWHP whenever the solar field is warm enough. The minimum working temperature of the BWHP is $-15^{\circ} \mathrm{C}$ and this control strategy does not allow the BWHP to work when the sun is gone. As a result, during winter time the AWHP is mainly used, increasing the electricity consumption in nearly $1800 \mathrm{kWh} /$ year. With a control strategy that allows to compare the efficiency of both HPs, results in $11 \%$ more primary energy savings and higher solar thermal production (as the DualSun PVT panels work as evaporator when the sun is gone). This leads to make use of $82.3 \%$ of the heat provided by the PVT panels and, by means of the BWHP, provide $66.9 \%$ of the heat needed in the system. The optimal cases are obtained with bigger tanks, but due to space limitations option $5(100 \mathrm{~kg} / \mathrm{h} \cdot \mathrm{panel})$ with the efficiency-dependent control is chosen, with the following parameters: a flow rate in the DualSun panels of 100 $\mathrm{kg} / \mathrm{h}$. panel, solar tilt of $35^{\circ}$, volumes of $0.2 \mathrm{~m} 3$ for the buffer tank, $1.3 \mathrm{~m} 3$ for the DHW tank, and $1 \mathrm{~m} 3 \mathrm{for} \mathrm{SH}$ tank, with a DHW setpoint of $50^{\circ} \mathrm{C}$ and the position of the sensor at the top of the tank (in heating mode).

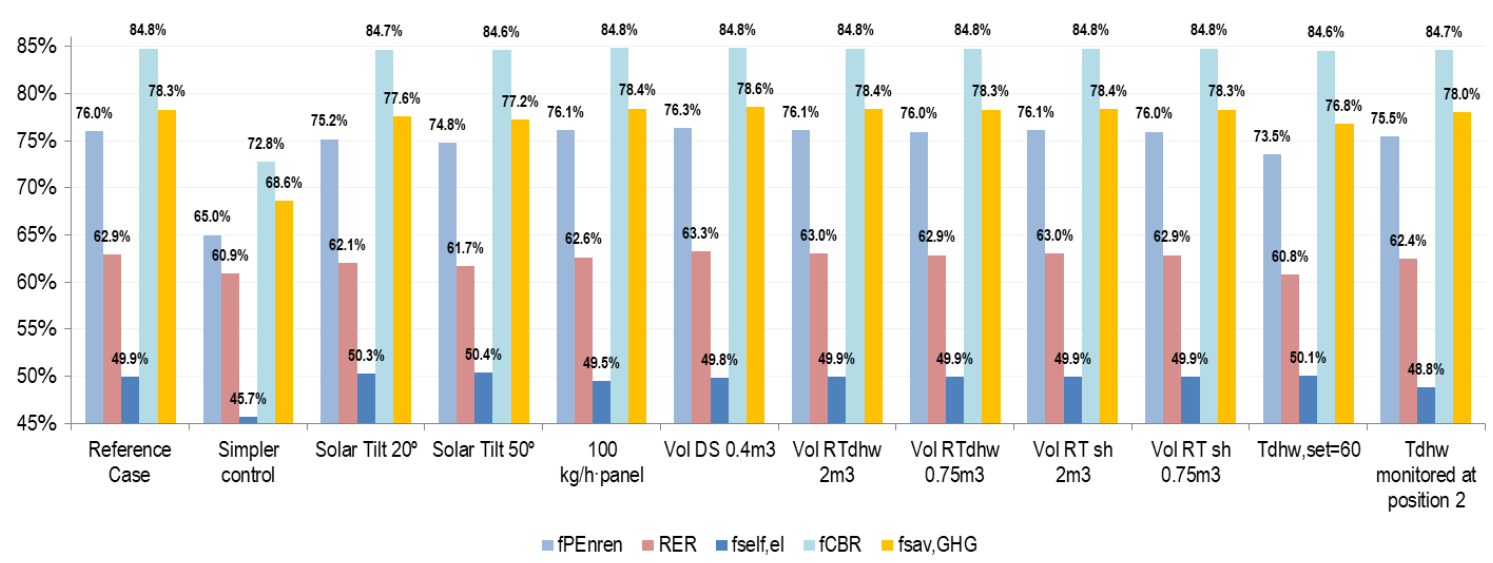

Fig. 8 Parametric Study for TP4-1 in Madrid demo site

The estimated TP4 annual KPIs are shown in Tab.9 where the savings are compared to the mostly gas-fueled baseline in Madrid demo case. Considering only AWHP supply for heating and cooling without PVT-drivenBWHP, the simulation estimates 41.3 MWh PEnren consumption, SCOP=2.7 and SEER=4.3. It means the DualSun solar PVT integration with BDR BWHP in TP4 would reach $\mathrm{f}_{\text {sav,PEnren }}=54 \%$ and increased SCOP=3.59 compared to AWHP alone since it runs as support in heating mode .

Tab. 9 Estimated annual KPIs for TP4-1 in Madrid demo site

\begin{tabular}{|c|c|c|c|c|c|c|c|c|c|c|}
\hline$\eta_{D S, 18^{\circ} \mathrm{C}}^{\text {gross }}$ & $\mathbf{f}_{\text {sol,th }}$ & $\eta_{D S, e l}^{\text {gross }}$ & $f_{\text {self }, e l}$ & $T E R$ & $d T_{t a n k, D H W}$ & $d T_{t a n k, S H / S C}$ & $R E R$ & $f_{\text {sav }, P E_{\text {nren }}}$ & $f_{\text {sav, GHG }}$ & $f_{C B R^{1}}$ \\
\hline $20.3 \%$ & $66.9 \%$ & $16.4 \%$ & $49.5 \%$ & 1.2 & $16 \mathrm{~K}$ & $2 \mathrm{~K}$ & $62.6 \%$ & $76.1 \%$ & $70.3 \%$ & $84.8 \%$ \\
\hline
\end{tabular}

\section{Conclusion}

The current work managed simulation studies about design and sizing of HP, thermal storage, solar collectors that allow for selecting four appropriate configurations of the TPs for their respective demo sites: small residential building in Berlin, Germany (TP1), small residential building in Riga, Latvia (TP2), tertiary civic center in Saint Cugat, Spain (TP3) and large social-housing apartment in Madrid, Spain (TP4) with annual savings results in terms of non-renewable primary energy consumption, GHG emissions and operating costs. In parallel, other configurations of the four TPs have been selected similarly to end up with the preliminary definition of eight SunHorizon demo pilots. The annual savings are ranging from 33 to $70 \%$ regarding GHG emissions, from 30 to $85 \%$ regarding the operation costs. It depends in a large extent on the demo site localization and existing system and verifies the expectation that the larger solar panels area, the higher the savings up to a limit, as illustrated in

\footnotetext{
${ }^{1}$ Most of the savings are obtained by removing the gas contract from the dwellings.
} 
Fig. 5 for TP1. For the TP1, TP3 solar thermal systems, it emphasizes the requirement of excess solar heat dissipation in building context with summer fluctuating heat load, that is facing in the other hand to the urban heat island reduction issue, whenever no detrimental operation cost effects were detected. It shows also rather flat optimal tank size for all TPs, mostly ending with selection of smallest tank in the range to lower the installation costs.

The previous descriptions of control and the simulations analysis showed that evolutions from original single component approach are required by HP controller manufacturer to run efficiently the systems. Indeed, it's the flexible device connected to stable energy network to ensure that the end-user temperature demand is satisfied, to look carefully to the solar REN source state and storage, to optimize overall energy savings sometimes against its pure own performance, or require to run HP internal pump to flow solar in heating circuit, while still considering hardware safety temperature limitation (bypass valve mostly required).

These system models and simulation results are being used for the design of specific tests following the semivirtual approach (Chèze et al., 2018) and to compare with the test results before installing the TPs on-site in 2021. The TRNSYS dynamic simulation models are currently used for the development of advanced control to be demonstrated in Riga and Sant Cugat sites. They will be run again at the end of the demonstration phase for the comparison with the performance monitoring data and the estimation of the savings, and in replication and exploitation case studies where the TPs may compete each other's or against single HP or PV+HP. Beyond project end, these models are the basis of either in-depth system model development with interested industrial partners or simplified system model for sizing tool.

\section{Acknowledgments}

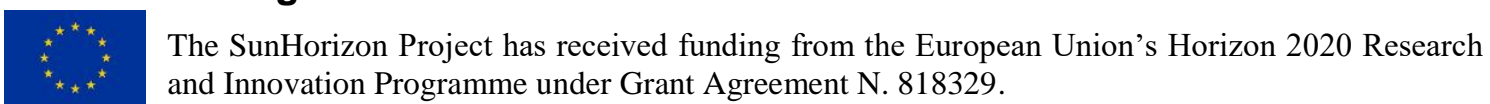

\section{References}

CARTIF, CEA, CNR ITAE, Checkwatt, RINA-Consulting, BDR THERMEA, Ratiotherm, Fahrenheit, Dualsun, Boostheat, TVPsolar, Exergy, EMVS, VEOLIA, AJSCV, Riga University, GRE-Liège, 2019. KPIs assessment based methodology (Public report No. D2.4), SunHorizon no. 818329. INEA, EC, http://www.SunHorizonproject.eu/wp-content/uploads/2019/12/D2.4-KPI-assessment.pdf. (last access 24/07/2020)

CEA, RINA-Consulting, Schneider Electric, Boostheat, CNR ITAE, CARTIF, AJSCV, GRE-Liège, BDR THERMEA, VEOLIA, Riga University, EMVS, 2020. Report on baseline and boundary conditions of SunHorizon demo sites, including monitoring aspects (Public report No. D6.1), SunHorizon no. 818329. INEA, EC, http://www.SunHorizon-project.eu/wp-content/uploads/2020/07/D6.1-demo-energy-audit.pdf. (last access 24/07/2020)

Chèze, D., Lamaison, N., Breitenbach, P., Fuligni, F., 2018. Comparative dynamic performance tests of two real technology packages for buildings heating system retrofit. EuroSun 2018. doi:10.18086/eurosun2018.01.07

Drück, Harald. 2006. Stratified fluid storage tank with four internal heat exchangers, ten connections for direct charge and discharge and an internal electrical heater -Type 340. TRNSYS. ITW Stuttgart: Transsolar.

H2020 Innovation Action GA818329, http://www.SunHorizon-project.eu/ (last access 24/07/2020)

Haller, Michel, Bengt Perers, Chris Bales, Janne Paavilainen, Antoine Dalibard, Stefan Fischer, and Erik Bertram. 2012. TRNSYS Type832v5.00 Dynamic Collector Model.

Jordan, U., Vajen, K., Kassel, U., 2005. DHWcalc: Program to generate domestic hot water profiles with statistical means for user defined conditions, ISES Solar World Congress, Orlando (US), p. 6.

IEA. 2018. Global Energy and CO2 Status Report 2017

McKenna, E., Thomson, M., 2016. High-resolution stochastic integrated thermal-electrical domestic demand model. Applied Energy 165, 445-461. https://doi.org/10.1016/j.apenergy.2015.12.089

ODYSSEE, 2018. Energy efficiency trends in buildings 